\title{
Elasticity and Anisotropy of Titanium Oxide $\mathrm{Ti}_{\mathrm{x}} \mathrm{O}_{\mathrm{y}}$
}

\author{
Yan-Ting LUO and Zhi-Qian CHEN ${ }^{\mathrm{a}}$ \\ Faculty of Materials and Energy, Southwest University, Chongqing 400715, China \\ achen_zq@swu.edu.cn
}

\begin{abstract}
The elastic properties and their anisotropies of $\mathrm{Ti}_{\mathrm{x}} \mathrm{O}_{\mathrm{y}}\left(\mathrm{TiO}, \mathrm{TiO}_{2}\right.$, $\mathrm{Ti}_{2} \mathrm{O}_{3}, \mathrm{Ti}_{3} \mathrm{O}, \mathrm{Ti}_{3} \mathrm{O}_{5}$ ) were investigated based on first-principles calculations with the generalized gradient approximation (GGA). The elastic constants and modulus, Poisson's ratio and universal anisotropic index were obtained. The bonds properties of the five materials were analyzed through Poisson's ratio and Pugh modulus ratio $(\mathrm{G} / \mathrm{B})$. The five titanium oxides are elastically anisotropic. Details of anisotropies were demonstrated in 3D plots.
\end{abstract}

Keywords: Titanium Oxide; first-principles; elasticity; anisotropy

\section{Introduction}

Titanium dioxide $\left(\mathrm{TiO}_{2}\right)$ is one of the best known wide band gap semiconductors with many unique properties like excellent photo activity, long-term stability, low cost and non-toxicity, which make it become the most common uses for photo catalytic material. A number of experimental and theoretical studies indicate that $\mathrm{TiO}_{2}$ has many polymorphs, such as rutile $(\mathrm{P} 42 / \mathrm{mnm})$, anatase (I41/amd) and brookite $(\mathrm{Pbca})^{[1-3]}$. However, lots of researches focus on titanium dioxide, but the discussions of other titanium oxides are less. In this paper, the elastic properties and their anisotropies of $\mathrm{Ti}_{\mathrm{x}} \mathrm{O}_{\mathrm{y}}\left(\mathrm{TiO}, \mathrm{TiO}_{2}, \mathrm{Ti}_{2} \mathrm{O}_{3}, \mathrm{Ti}_{3} \mathrm{O}, \mathrm{Ti}_{3} \mathrm{O}_{5}\right)$ are investigated, which is significant to the practical application of titanium oxide.

\section{Calculation Methods and Theory}

\subsection{Calculation parameter and model}

The crystal structure of five titanium oxides $\left(\mathrm{TiO}, \mathrm{TiO}_{2}, \mathrm{Ti}_{2} \mathrm{O}_{3}, \mathrm{Ti}_{3} \mathrm{O}, \mathrm{Ti}_{3} \mathrm{O}_{5}\right)$ are shown in Figure 1. The first principles calculation based on DFT ${ }^{[4]}$ was used with the aid of the CASTEP [5] program. The exchange and correlation potentials were Perdew-Burke-Ernzerhof method based on generalized gradient approximation (GGA) ${ }^{[6]}$. The crystal wave function was expanded by the plane wave basis set, and the interaction potential for ion core and valence electron was determined based on the ultrasoft pseudopotential $^{[7]}$. 


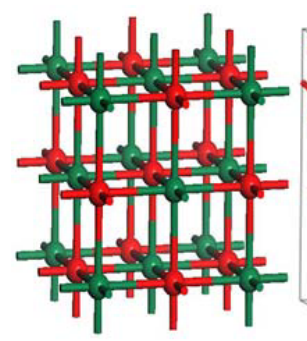

(a)

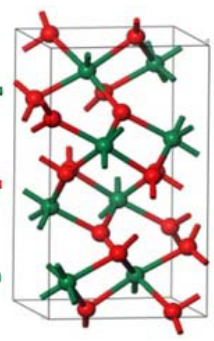

(b)

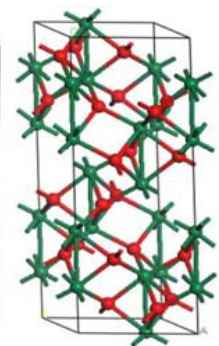

(c)

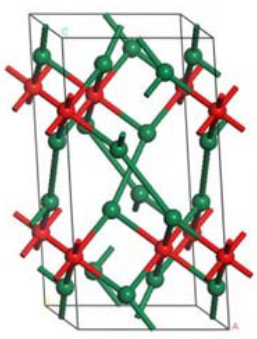

(d)

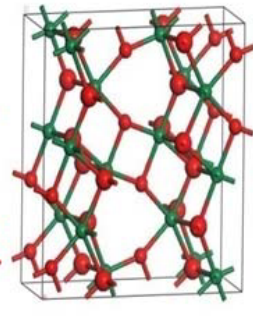

(e)

Figure 1. The crystal Structures of the five $\mathrm{Ti}_{\mathrm{x}} \mathrm{O}_{\mathrm{y}}$. The small green spheres and red spheres denote $\mathrm{Ti}$ and $\mathrm{O}$ atoms, respectively. (a) $\mathrm{TiO}(\mathrm{Fm} 3 \mathrm{~m})$, (b) Brookite of $\mathrm{TiO}_{2}(\mathrm{Pbca})$, (c) $\mathrm{Ti}_{2} \mathrm{O}_{3}(\mathrm{R}-3 \mathrm{C})$, (d) $\mathrm{Ti}_{3} \mathrm{O}(\mathrm{P}-31 \mathrm{c})$, (e) Anosovite of $\mathrm{Ti}_{3} \mathrm{O}_{5}(\mathrm{Cmcm})$.

\subsection{Elastic properties and their anisotropies}

To calculate the bulk modulus and shear modulus, we refer to the models of Voigt and Reuss, respectively. The bulk modulus and shear modulus for monoclinic structure are given by ${ }^{[8]}$ :

$$
\begin{aligned}
& B_{V}=(1 / 9)\left[C_{11}+C_{22}+C_{33}+2\left(C_{12}+C_{13}+C_{23}\right)\right] \\
& G_{V}=(1 / 15)\left[C_{11}+C_{22}+C_{33}+3\left(C_{44}+C_{55}+C_{66}\right)-\left(C_{12}+C_{13}+C_{23}\right)\right] \\
& B_{R}=\left[\left(S_{11}+S_{22}+S_{33}\right)+2\left(S_{12}+S_{13}+S_{23}\right)\right]^{-1} \\
& B_{R}=(1 / 15)\left[4\left(S_{11}+S_{22}+S_{33}\right)-4\left(S_{12}+S_{13}+S_{23}\right)+3\left(S_{44}+S_{55}+S_{66}\right)\right]^{-1}
\end{aligned}
$$

Based on extreme value principle, Hill ${ }^{[9]}$ has proved that Voigt's and Reuss's models are the upper and lower limits of the elastic constant, respectively. The arithmetic mean Voigt-Reuss-Hill (VRH) value is closer to the experimental result.

$$
B=\left(B_{V}+B_{R}\right) / 2, G=\left(G_{V}+G_{R}\right) / 2
$$

Using Hill's value of bulk modulus and shear modulus, the Young's modulus and Poisson's ratio for each material under polycrystalline system were obtained:

$$
E=(9 B G) /(3 B+G), \quad v=\frac{3 B-2 G}{2(3 B+G)}
$$

To conduct quantitative research on the anisotropy of a single crystal, we calculated the universal anisotropic index $A^{U[10]}$ which describes the anisotropy of elasticity for single crystals.

$$
A^{U}=5 G_{V} / G_{R}+B_{V} / B_{R}-6 \geq 0
$$

Here $A^{U}=0$ refers to a locally isotropic single crystal. Any departure from zero corresponds to a degree of elastic anisotropy possessed by the crystal. 


\section{Calculation Results and Discussion}

\subsection{Structural parameters}

We used GGA method obtained the structural parameters of the five $\mathrm{Ti}_{\mathrm{x}} \mathrm{O}_{\mathrm{y}}$, and the results of geometric parameters after optimization list in Table 1. From table 1, it can be seen that the parameters of five titanium oxides are different. The calculations suggest that the density of $\mathrm{Ti}_{2} \mathrm{O}_{3}$ is the largest among these five materials while $\mathrm{Ti}_{3} \mathrm{O}_{5}$ is opposite.

TABLE 1. THE CALCULATED LATTICE PARAMETERS, VOLUME PER FORMULA

AND DENSITIES FOR FIVE TITANIUM OXIDES USING GGA(GENERALIZED GRADIENT APPROXIMATION). $\mathrm{TI}_{\mathrm{X}} \mathrm{O}_{\mathrm{Y}}$ STRUCTURE CONSTANTS $A, B, C[\AA]$, VOLUME $V\left[\AA^{3}\right]$, AND DENSITY $P\left[{\left.\mathrm{G} . \mathrm{CM}^{-3}\right]}^{-3}\right.$

\begin{tabular}{cccccc}
\hline name & $\mathrm{TiO}$ & $\mathrm{TiO}_{2}$ & $\mathrm{Ti}_{2} \mathrm{O}_{3}$ & $\mathrm{Ti}_{3} \mathrm{O}$ & $\mathrm{Ti}_{3} \mathrm{O}_{5}$ \\
Space group & $\mathrm{Fm} 3 \mathrm{~m}$ & $\mathrm{Pbca}$ & $\mathrm{R}-3 \mathrm{C}$ & $\mathrm{P}-31 \mathrm{c}$ & $\mathrm{Cmcm}$ \\
\hline $\mathrm{a}$ & 4.29 & 9.28 & 5.13 & 5.17 & 3.74 \\
$\mathrm{~b}$ & 4.29 & 5.52 & 5.13 & 5.17 & 10.08 \\
$\mathrm{c}$ & 4.29 & 5.19 & 14.16 & 9.52 & 10.17 \\
$\mathrm{~V}$ & 79.23 & 265.66 & 322.79 & 220.35 & 383.62 \\
$\rho\left(\mathrm{g} / \mathrm{cm}^{3}\right)$ & 5.38 & 4.01 & 5.45 & 4.84 & 3.90 \\
\hline
\end{tabular}

\subsection{Elastic properties and their anisotropies}

Elastic constants characterize the reaction of crystal lattice to external stress within the elastic limit. Table 2 shows the elastic constants and elastic modulus of these five titanium oxides.

Some parameters for polycrystals, bulk modulus $B$, shear modulus $G$, Young's modulus $E$, Pugh modulus ratio $G / B$, and Poisson's ratio are listed in Table 2. According to Pugh's criterion ${ }^{[11]}$, materials with Pugh modulus ratio $G / B>0.57$ show brittleness, whereas materials with $G / B<0.57$ show ductility. The results of $G / B$ in Table 2 indicate that the former materials $\left(\mathrm{TiO}, \mathrm{TiO}_{2}, \mathrm{Ti}_{2} \mathrm{O}_{3}\right.$ and $\left.\mathrm{Ti}_{3} \mathrm{O}\right)$ show ductility, and the sequence of $G / B$ is $\mathrm{Ti}_{2} \mathrm{O} 3(0.498)>\mathrm{Ti}_{3} \mathrm{O}(0.457)>\mathrm{TiO} 2(0.443)>\mathrm{TiO}(0.382)$, indicating that $\mathrm{Ti}_{2} \mathrm{O} 3$ possesses the highest directing property of bonds, $\mathrm{TiO}$ conversely possesses the lowest directing property of bonds. The result of $G / B$ for $\mathrm{Ti}_{3} \mathrm{O} 5$ equals to 0.718 , indicating that $\mathrm{Ti}_{3} \mathrm{O} 5$ can be classified as brittle material. Moreover, the lowest $G / B$ value of $\mathrm{TiO}$ in calculations indicates that it has the best ductility among these five materials. For central force solids Poisson's ratio is bounded by the lower limit of 0.25 and the upper limit of 0.5. The Poisson's ratio for $\mathrm{TiO}, \mathrm{TiO}_{2}, \mathrm{Ti}_{2} \mathrm{O}_{3}, \mathrm{Ti}_{3} \mathrm{O}, \mathrm{Ti}_{3} \mathrm{O}_{5}$ are $0.330,0.307,0.287,0.302$ and 0.210 , respectively. When $v$ is between 0.25 and 0.5 , it means that the atomic binding force is a central force. Table 2 shows that the atomic binding force of the former materials are central force. TiO possesses the highest $v(0.330)$, suggesting that it has the weakest stability among the five titanium oxides within the process of resisting shear deformation. 
TABLE 2 ELASTIC CONSTANTS $C_{I J}[G P A]$, SHEAR MODULUS $G[G P A]$, BULK MODULUS $B[G P A]$, YOUNG'S MODULUS $E[G P A]$, PUGH MODULUS RATIO $G / B$ AND POSSION'S RATIO $N$

\begin{tabular}{cccccc}
\hline name & $\mathrm{TiO}$ & $\mathrm{TiO}_{2}$ & $\mathrm{Ti}_{2} \mathrm{O}_{3}$ & $\mathrm{Ti}_{3} \mathrm{O}$ & $\mathrm{Ti}_{3} \mathrm{O}_{5}$ \\
\hline$C_{11}$ & 511 & 278 & 252 & 216 & 305 \\
$C_{12}$ & 53 & 123 & 97 & 131 & 126 \\
$C_{13}$ & 53 & 141 & 108 & 79 & 103 \\
$C_{22}$ & 511 & 252 & 252 & 216 & 213 \\
$C_{23}$ & 53 & 120 & 107 & 79 & 62 \\
$C_{33}$ & 511 & 284 & 361 & 304 & 172 \\
$C_{44}$ & 31 & 94 & 74 & 93 & 55 \\
$C_{55}$ & 31 & 95 & 74 & 93 & 45 \\
$C_{66}$ & 31 & 61 & 77 & 43 & 55 \\
$G$ & 78 & 77 & 81 & 67 & 95 \\
$B$ & 205 & 175 & 163 & 146 & 133 \\
$E$ & 209 & 202 & 209 & 173 & 231 \\
$G / B$ & 0.382 & 0.443 & 0.498 & 0.457 & 0.718 \\
$v$ & 0.330 & 0.307 & 0.287 & 0.302 & 0.210 \\
$A^{U}$ & 6.6849 & 0.1708 & 0.1606 & 1.5695 & 0.3543 \\
\hline
\end{tabular}

From the all figures $A^{U}$ unequal to zero, one knows that all five titanium dioxides are anisotropic and $\mathrm{TiO}$ is the most anisotropic. But one cannot know the details of the anisotropy. In order to see clearly the elastic anisotropies for $\mathrm{TiO}, \mathrm{TiO}_{2}, \mathrm{Ti}_{2} \mathrm{O}_{3}, \mathrm{Ti}_{3} \mathrm{O}$ and $\mathrm{Ti}_{3} \mathrm{O}_{5}$, we plot three dimensional surfaces of modulus in Figure 2. The formulas are as follow ${ }^{[12]}$ :

$$
\begin{array}{r}
E^{-1}=1_{1}^{4} S_{11}+21_{1}^{2} 1_{2}^{2} S_{12}+21_{1}^{2} 1_{3}^{2} S_{13}+21_{1}^{3} 1_{3} S_{15}+21_{2}^{4} S_{22}+21_{2}^{2} 1_{3}^{2} S_{23} \\
+21_{1} 1_{2}^{2} 1_{3} S_{25}+1_{3}^{4} S_{33}+21_{1} 1_{3}^{3} S_{35}+1_{2}^{2} 1_{3}^{2} S_{44}+21_{1} 1_{2}^{1} 1_{3} S_{45} \\
+1_{1}^{2} 1_{3}^{2} S_{55}+1_{1}^{2} 1_{2}^{2} S_{66}
\end{array}
$$

In above formulas, $S_{i j}$ stand for elastic compliance constants, and $l_{1}, l_{2}$ and $l_{3}$ are the directional cosine.
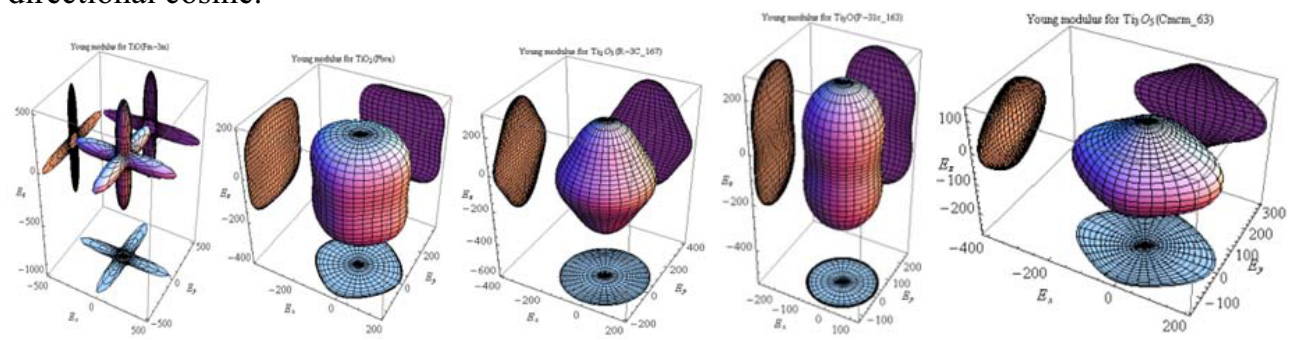

Figure 2. The directional dependence of Young's modulus for $\mathrm{TiO}, \mathrm{TiO}_{2}, \mathrm{Ti}_{2} \mathrm{O}_{3}, \mathrm{Ti}_{3} \mathrm{O}$ and $\mathrm{Ti}_{3} \mathrm{O}_{5}$. 


\section{Conclusions}

In this paper, we calculated the elasticity and anisotropy of $\mathrm{Ti}_{\mathrm{x}} \mathrm{O}_{\mathrm{y}}$. The calculated results show that all the five materials are elastically anisotropic. The Anisotropic index $A^{U}$, shows the sequences of $\mathrm{Ti}_{\mathrm{x}} \mathrm{O}_{\mathrm{y}}$ is $\mathrm{Ti}_{2} \mathrm{O}_{3}<\mathrm{TiO}_{2}<\mathrm{Ti}_{3} \mathrm{O}_{5}<\mathrm{Ti}_{3} \mathrm{O}<\mathrm{TiO}$. TiO, $\mathrm{TiO}_{2}, \mathrm{Ti}_{2} \mathrm{O}_{3}$ and $\mathrm{Ti}_{3} \mathrm{O}$ show ductility, while $\mathrm{Ti}_{3} \mathrm{O}_{5}$ shows brittleness.

\section{References}

1. H. Sato, S. Eedo, M. Sugiyama, et al. Baddeleyite-Type High-Pressure Phase of $\mathrm{TiO}_{2}$. SCIENCE, 1990.251-786.

2. Y.C. Ding, B. Xiao. Anisotropic elasticity, sound velocity and thermal conductivity of $\mathrm{TiO}_{2}$ polymorphs from first principles calculations. Computational Materials Science, 2014,82,202-218.

3. X.G. Ma, P. Liang, L. Miao, et al. Pressure-induced phase transition and elastic properties of $\mathrm{TiO}_{2}$ polymorphs. Phys. Status Solidi B, 2009,1-8.

4. P. Hohenberg, W. Kohn. Inhomogeneous electron gas. Phys Rev B,1964,136: 864-871.

5. M. D. Segall, P. J. D. Lindan, M.J. Probert, First-principles simulation: ideas, illustrations and the CASTEP code. J. Phys. C 14 (2002) 2717.

6. J. P. Perdew, K. Burke, M. Ernzerhof, Generalized Gradient Approximation Made Simple. Phys. Rev. Lett. 77 (1996) 3865.

7. D.Vanderbilt, Soft self-consistent pseudopotentials in a generalized eigenvalue formalism, Phys. Rev. B, 1990 (41): 7892-7895.

8. J. P. Watt, Hashin-Shtrikman bounds on the effective elastic moduli of polycrystals with monoclinic symmetry. J. Appl. Phys. 51 (1980) 1520.

9. R. Hill, The elastic behaviour of a crystalline aggregate. Proc Phys Soc, 1952, 65: 350-354.

10. S.I. Ranganathan, M.Ostoja-Starzewski, Universal elastic anisotropy index. Phys Rev Lett, 2008,101: 055504.

11. S.F. Pugh, XCII. Relations between the elastic moduli and the plastic properties of polycrystalline pure metals. Philos Mag,1954,45: 823-843.

12. J.F. Nye, Physical Properties of Crystals. Oxford: Clarendon Press, 1964 